\title{
Caracterização de massas cerâmicas do estado de S. Paulo para produção de agregados leves para concreto
}

\section{(S. Paulo state ceramic material characterization for the production of concrete lightweight aggregate)}

\author{
B. C. Santis ${ }^{1}$, E. P. Sichieri ${ }^{1}$, J. A. Rossignolo ${ }^{2}$, G. Ferreira ${ }^{3}$, J. Fiorelli ${ }^{4}$ \\ ${ }^{1}$ Instituto de Arquitetura e Urbanismo de S. Carlos - USP, Av. Trabalhador São-carlense 400, \\ S. Carlos, SP 13566-590 \\ ${ }^{2}$ Faculdade de Zootecnia e Engenharia de Alimentos - USP, Av. Duque de Caxias Norte 225, \\ Campus da USP, Pirassununga, SP 13635-900 \\ ${ }^{3}$ Instituto de Química de S. Carlos - USP, Av. Trabalhador São-carlense 400, S. Carlos, SP 13566-590 \\ ${ }^{4}$ Faculdade de Zootecnia e Engenharia de Alimentos - USP, Av. Duque de Caxias Norte 225, \\ Campus da USP, Pirassununga, SP 13635-900
}

\begin{abstract}
Resumo
Este trabalho tem por objetivo a caracterização de diferentes massas cerâmicas do estado de S. Paulo para a produção de agregados leves de argila calcinada visando à utilização em concretos de cimento Portland. A caracterização das massas cerâmicas deu-se por meio das técnicas de limites de liquidez e plasticidade, análise granulométrica, análise química e difração de raios X. Os corpos de prova confeccionados com essas massas cerâmicas, queimados a $900{ }^{\circ} \mathrm{C}$, foram caracterizados por meio da avaliação da retração linear, absorção de água, porosidade aparente, massa específica aparente, expansão por umidade e resistência à compressão. Os resultados desta pesquisa indicaram a viabilidade da produção de agregados leves de argila calcinada para utilização em concretos e os valores da massa específica $\left(1,555\right.$ a $\left.1,785 \mathrm{~kg} / \mathrm{m}^{3}\right)$ e da resistência à compressão $(18,0$ a 55,8 MPa) apresentaram-se em um patamar intermediário entre os observados para a argila expandida (agregado leve comercial) e para o agregado convencional (basalto).

Palavras-chave: massas cerâmicas, agregados leves de argila calcinada, concretos leves.
\end{abstract}

Abstract

This paper aims the characterization of different S. Paulo state ceramic material for the production of calcined Clay lightweight aggregates in order to use in Portland cement concretes. The characterization of ceramic material was made by techniques of liquid and plasticity limits, particle size analysis, chemical analysis and X-ray diffraction. The specimens made from these ceramic materials, burned at $900{ }^{\circ} \mathrm{C}$, were characterized by evaluating of linear shrinkage, water absorption, apparent porosity, specific mass, moisture expansion and compressive strength. Results of this research indicated the viability of production of calcined clay lightweight aggregate for use in concrete and the values of specific mass (1.555 to $1.785 \mathrm{~kg} / \mathrm{m}^{3}$ ) and compressive strength (18.0 to $55.8 \mathrm{MPa}$ ) presented at a intermediate level between those observed for the expanded clay (commercial lightweight aggregate)and the conventional aggregate (basalt).

Keywords: cerâmic material, calcined clay lightweight aggregates, lightweight concrete.

\section{INTRODUÇÃOO}

O concreto com agregados leves, ou concreto leve estrutural, apresenta-se como um material de construção consagrado em todo o mundo, com aplicação em diversas áreas da construção civil. A ampla utilização desse material em todo o mundo é particularmente atribuída aos benefícios promovidos pela redução da massa específica do concreto, como a redução de esforços na estrutura das edificações, a economia com formas e cimbramento, bem como a diminuição dos custos com transporte e montagem de construções pré-fabricadas [1-4]. Entretanto, podese afirmar que no Brasil a utilização dos concretos com agregados leves ainda é modesta, frente ao seu potencial de utilização, estando concentrada no estado de S. Paulo e em estados vizinhos, dada a localização da fábrica de argila expandida CINEXPAN, em Várzea Paulista - SP, único fabricante de agregados leves no país. Por se tratar de uma única empresa produtora, o alto custo do transporte a longas distâncias dificulta a disseminação dessa tecnologia por todo o território nacional. Com isso, constata-se que desde o início da produção de argila expandida no Brasil, em 1968, a maioria das aplicações dos concretos leves estruturais 
ocorreu no estado de S. Paulo, em elementos estruturais pré-fabricados e na estrutura de edificações de múltiplos pavimentos moldado in loco, em especial nas lajes [4-7].

Uma alternativa para a disseminação da tecnologia do concreto leve estrutural por todo território nacional seria a produção de agregados leves de argila calcinada, utilizando a cerâmica vermelha, já que existem cerca de 11.000 empresas produtoras de cerâmica vermelha espalhadas por todo o território nacional e que, com pequenas modificações em suas linhas de produção, essas empresas poderiam produzir agregados leves de argila calcinada como mais um de seus produtos comerciais [8].

Estudos preliminares indicam a viabilidade de produção e utilização desse tipo de agregado leve na construção civil, utilizando-se os pólos produtivos de cerâmica vermelha espalhados por todo o território nacional [9-13].

Assim, este trabalho tem como objetivo a análise da viabilidade da utilização da cerâmica vermelha na produção de agregados leves de argila calcinada para a utilização em concretos estruturais.

\section{MATERIAIS E MÉTODOS}

Foram coletadas matérias primas (solos) de cinco diferentes empresas fabricantes de produtos cerâmicos no estado de S. Paulo, em cinco diferentes cidades: Tambaú, Porto Ferreira, Ubarana, Leme e Itu. Nas amostras de solo coletadas "in natura" foram realizadas as seguintes análises: determinação dos limites de liquidez (LL) e plasticidade (LP), análise granulométrica e determinação da massa específica dos sólidos, difração de raios $\mathrm{X}$ (DRX), espectrometria de fluorescência de raios X (FRX) e as análise térmica diferencial (ATD) e termogravimétrica (ATG) [14-17].

Para a confecção dos corpos de prova de cerâmica vermelha, com $10 \mathrm{~cm}$ de comprimento e $1,5 \mathrm{~cm}$ de diâmetro, as amostras de solo foram destorroadas, moídas (com diâmetro final das partículas inferior à $0,2 \mathrm{~mm}$ ) e secas em estufa a $100{ }^{\circ} \mathrm{C}$. Em seguida, as amostras de solo foram submetidas ao ensaio de determinação da umidade natural. A partir dos valores de quantidade de água contida em cada uma das amostras, assim como seus limites de liquidez e plasticidade, as massas para extrusão foram preparadas adicionando-se quantidades de água que as conferiam consistência próximas aos seus limites de plasticidades, Tabela I.

Tabela I - Limites de plasticidade (LP) das amostras de solo e umidade utilizada para extrusão dos corpos de prova.

[Table I - Plastic limit (PL) of the soil samples and moisture used for extrusion of the samples.]

\begin{tabular}{cccccc}
\hline & Ubarana & $\begin{array}{c}\text { Porto } \\
\text { Ferreira }\end{array}$ & Itu & Tambaú & Leme \\
\hline $\mathrm{LP}$ & 19,1 & 30,7 & 21,7 & 28,1 & 25,9 \\
$\mathrm{~W}(\%)^{1}$ & 5,8 & 4,7 & 5,0 & 5,0 & 2,4 \\
$\mathrm{~W}_{\mathrm{e}}(\%)^{2}$ & 19,4 & 27,5 & 18,2 & 31,6 & 27,8 \\
\hline${ }^{1}{\text { Umidade das amostras de solo, }{ }^{2} \text { umidade das amostras para a extrusão }}$
\end{tabular}

As massas cerâmicas foram extrudadas com umidades próximas de seus limites de plasticidade, levando-se em consideração a umidade já existente em cada uma delas, conforme ilustra a Tabela I, em uma maromba de escala laboratorial MVIG-05. Para a extrusão, utilizou-se boquilha de formato cilíndrico, com diâmetro de $15 \mathrm{~mm}$. Após a extrusão, os corpos de prova foram cortados em tamanhos de $10 \mathrm{~cm}$ de comprimento. Os corpos de prova permaneceram em estufa ventilada, a uma temperatura de $60{ }^{\circ} \mathrm{C}$ por $72 \mathrm{~h}$. Em seguida foram queimados em uma mufla a $900{ }^{\circ} \mathrm{C} / 60 \mathrm{~min}$ com rampa de aquecimento $4{ }^{\circ} \mathrm{C} / \mathrm{min}$ e de resfriamento $6{ }^{\circ} \mathrm{C} / \mathrm{min}$. Após a queima, os corpos de prova foram submetidos aos ensaios de retração linear, absorção de água (após imersão de $24 \mathrm{~h}$ ), porosidade aparente e massa específica aparente (após imersão por $48 \mathrm{~h}$ ), expansão por umidade e resistência à compressão, com corpos de prova com 3,0 cm de altura e 1,5 cm de diâmetro [18-20].

\section{RESULTADOS E DISCUSSÃO}

A apresentação dos resultados está dividida em duas etapas. A primeira consiste na caracterização das matérias primas e a segunda, na caracterização dos corpos de prova queimados.

A Tabela II apresenta os valores dos limites de liquidez, plasticidade, índice de plasticidade e massa específica das amostras de solo analisadas. Os valores do limite de liquidez das amostras variaram de $48,8 \%$ a $67,0 \%$. Já os valores do limite de plasticidade das matérias primas analisadas variaram de $19,1 \%$ a $30,7 \%$, conferindo às amostras índices de plasticidade (IP) entre $18,1 \%$ e $38,9 \%$, o que indica que todas as amostras analisadas podem ser classificadas como altamente plásticas (índice de plasticidade superior à 15\%) [19].

O limite de plasticidade representa a quantidade mínima de água a ser adicionada a uma amostra de solo para que a mesma obtenha características moldáveis. Dessa forma, amostras de solo com altos valores de limite de plasticidade necessitam de mais água para conformação do que amostras de solo com valores baixos de limite de plasticidade.

Para a moldagem por extrusão de peças cerâmicas os valores adequados para o limite de plasticidade e para o índice de plasticidade são, respectivamente, de $15 \%$ a $25 \%$ e de $10 \%$ a $35 \%$. As amostras de Ubarana e de Itu apresentaram valores de limites de plasticidade compreendidos entre $15 \%$ e $25 \%$ ( $19,1 \%$ e $21,7 \%$, respectivamente). Com relação ao índice de plasticidade, as amostras de Porto Ferreira, Leme e Itu foram as únicas que apresentaram valores compreendidos entre $10 \%$ e $35 \%(18,1 \%, 32,1 \%$ e $27,3 \%$, respectivamente). Portanto, a única amostra que apresentou limite de plasticidade e índice de plasticidade, compreendidos entre os valores adequados para a moldagem por extrusão foi a de Itu (21,7\% e 27,3\%, respectivamente) [19].

Os valores das massas específicas dos sólidos também são apresentados na Tabela II. O menor valor de massa específica encontrado foi na amostra de Tambaú $\left(2,360 \mathrm{~g} / \mathrm{cm}^{3}\right)$ e o maior na amostra de Ubarana $\left(2,695 \mathrm{~g} / \mathrm{cm}^{3}\right)$, o que pode 
Tabela II - Limites de liquidez, plasticidade, índice de plasticidade e massa específica das amostras de solo.

[Table II - Liquid and plastic limits, plasticity index and density of the soil samples.]

\begin{tabular}{ccccc}
\hline Amostra & $\mathrm{LL}^{(1)}(\%)$ & $\mathrm{LP}^{(2)}(\%)$ & $\mathrm{IP}^{(3)}(\%)$ & $\rho_{\mathrm{s}}{ }^{(4)}\left(\mathrm{g} / \mathrm{cm}^{3}\right)$ \\
\hline Tambaú & 67,0 & 28,1 & 38,9 & 2,360 \\
Porto Ferreira & 48,8 & 30,7 & 18,1 & 2,640 \\
Ubarana & 57,5 & 19,1 & 38,4 & 2,695 \\
Leme & 58,0 & 25,9 & 32,1 & 2,675 \\
Itu & 49,0 & 21,7 & 27,3 & 2,585 \\
\hline
\end{tabular}

${ }^{1}$ Limite de liquidez, ${ }^{2}$ Limite de plasticidade, ${ }^{3}$ Índice de plasticidade, ${ }^{4}$ Massa especifica dos sólidos.

Tabela III - Composição granulométrica das amostras de solo.

[Table III - Granulometric composition of the soil samples.]

\begin{tabular}{ccccccc}
\hline Amostra & $\begin{array}{c}\text { Argila } \\
(\%)\end{array}$ & $\begin{array}{c}\text { Silte } \\
(\%)\end{array}$ & $\begin{array}{c}\text { Areia fina } \\
(\%)\end{array}$ & $\begin{array}{c}\text { Areia média } \\
(\%)\end{array}$ & $\begin{array}{c}\text { Areia grossa } \\
(\%)\end{array}$ & $\begin{array}{c}\text { Pedregulho } \\
(\%)\end{array}$ \\
\hline Tambaú & 61 & 34 & 2 & 1 & 1 & 1 \\
Porto Ferreira & 48 & 28 & 17 & 6 & 1 & 0 \\
Ubarana & 53 & 19 & 24 & 3 & 1 & 0 \\
Leme & 48,5 & 37,5 & 10 & 3 & 1 & 0 \\
Itu & 50 & 31 & 6 & 9 & 4 & 0 \\
\hline
\end{tabular}

ser um indicativo de que os agregados produzidos com as amostras de solo de Ubarana apresentarão as maiores massas específicas dentre as amostras analisadas. Como a massa específica aparente está diretamente ligada à massa específica das peças queimadas, as peças conformadas com as amostras de maior massa específica aparente poderão apresentar maior densificação. A Tabela III apresenta o resultado da análise granulométrica das amostras de solo. Em todas as amostras analisadas, os teores de argila são predominantes, sendo que a amostra de Ubarana apresentou o maior teor de areia em sua composição (28\%), o que certamente contribuiu para o baixo valor do limite de plasticidade dessa amostra $(19,1 \%)$, já que a areia é dos principais materiais desplastificantes [20]. As amostras de Porto Ferreira e Leme apresentaram teores semelhantes de argila em suas composições (48\% e $48,5 \%$, respectivamente), o que contribuiu para que as duas amostras fossem conformadas com quantidades de água muito semelhantes $(27,5 \%$ e $27,8 \%)$, mesmo a amostra de Porto Ferreira apresentando um limite de plasticidade superior à amostra de Leme. $\mathrm{O}$ fato de todas as amostras apresentarem predominância de grãos finos (argila e silte) comprova suas características altamente plásticas [19].

As Figs. 1 a 5 ilustram os difratogramas de raios $X$ das amostras estudadas. Todas as amostras apresentam como principais características a presença de argilominerais. Todas as amostras apresentaram picos acentuados na faixa de $2 \theta=27^{\circ}$, que indicam a presença de quartzo livre em suas composições. Em nenhum dos casos verificou-se a presença de montmorilonita (argilomineral com características expansivas). Porém, todas as amostras apresentaram picos característicos de muscovita, argilomineral com

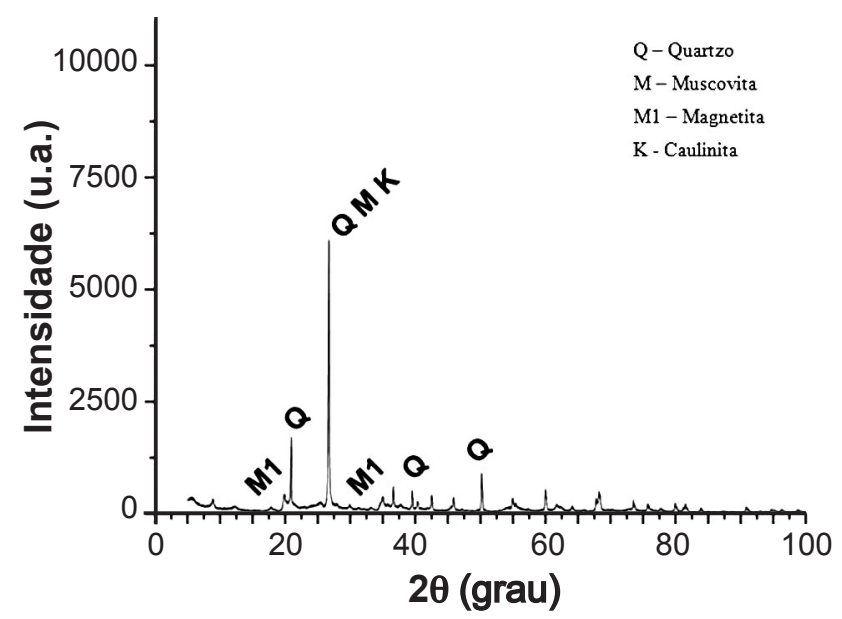

Figura 1: Difratograma de raios $\mathrm{X}$ da amostra de solo de Tambaú. [Figure 1: Tambaú's soil sample X-ray diffraction pattern.]

características expansivas. Além disso, as amostras de Porto Ferreira e Itu apresentaram picos característicos de ilita, que pertence ao grupo dos minerais com a estrutura da montmorilonita. Todas as amostras apresentam picos claros de hematita ou magnetita, o que está ligado à presença de ferro nas amostras, responsável pela coloração avermelhada das peças queimadas. Alem disso, os intensos picos identificados como quartzo indicam que estas amostras apresentarão melhoria na resistência a compressão, pois o quartzo é um dos cristais formadores da fase vítrea do agregado.

Analisando a Tabela IV, que apresenta a composição química das amostras, observa-se que todas as amostras apresentaram altos teores de dióxido de silício $\left(\mathrm{SiO}_{2}\right)$, 


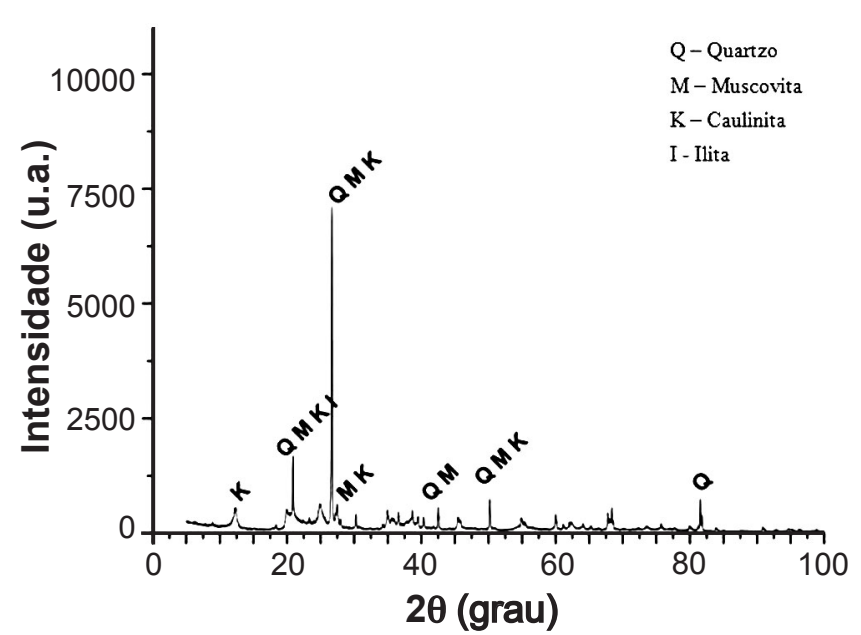

Figura 2: Difratograma de raios $\mathrm{X}$ da amostra de solo de Porto Ferreira.]

[Figure 2: Porto Ferreira's soil sample X-ray diffraction pattern.]

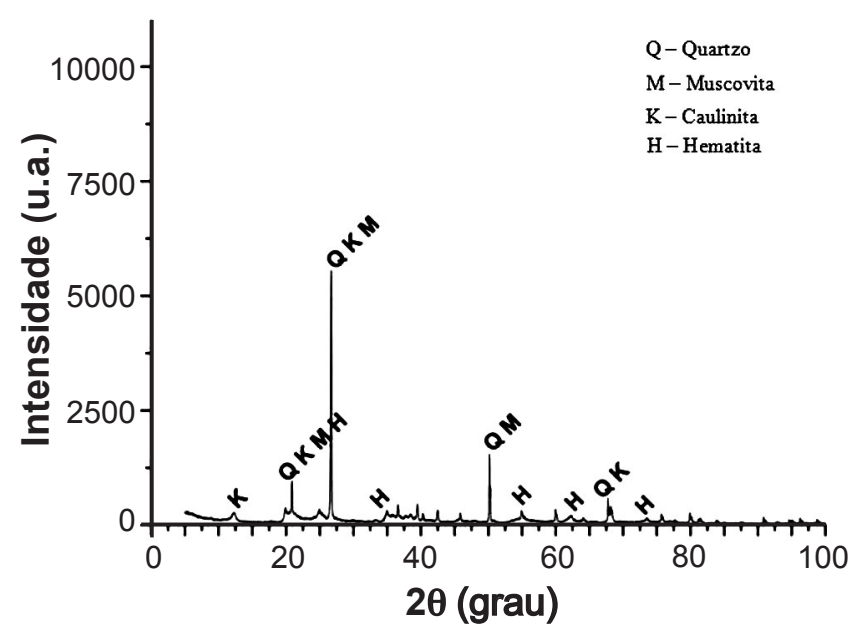

Figura 3: Difratograma de raios X da amostra de solo de Ubarana. [Figure 3: Ubarana's soil sample X-ray diffraction pattern.]

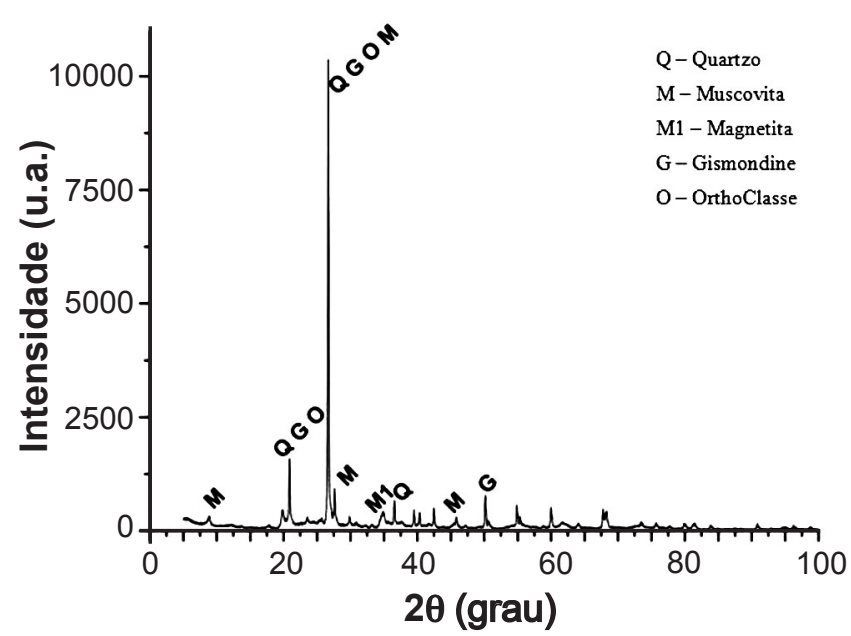

Figura 4: Difratograma de raios $\mathrm{X}$ da amostra de solo de Leme. [Figure 4: Leme's soil sample X-ray diffraction pattern.]

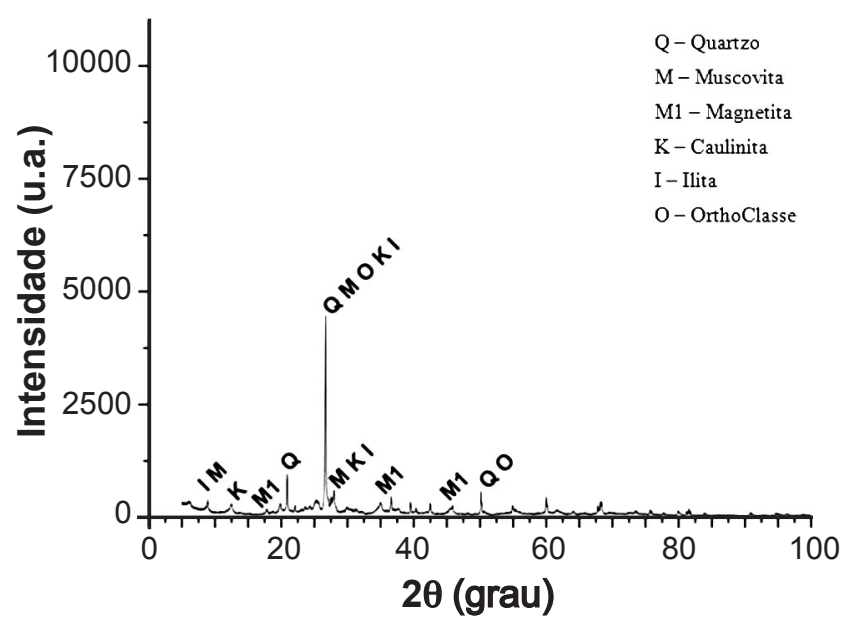

Figura 5: Difratograma de raios X da amostra de solo de Itu. [Figure 5: Itu's soil sample X-ray diffraction pattern.]

variando de 59,50\%, para a amostra de Porto Ferreira, a $68,18 \%$, para a amostra de Leme.

A presença de material vítreo nas massas cerâmicas $\left(\mathrm{SiO}_{2}\right.$ $+\mathrm{Al}_{2} \mathrm{O}_{3}$ ) pode conferir às peças queimadas maiores valores de resistência à compressão em função da maior vitrificação das peças. A presença de quantidades superiores a $1 \%$ de dióxido titânio $\left(\mathrm{TiO}_{2}\right)$ nas amostras de solo de Itu e Ubarana pode ser responsável pela cor acinzentada das mesmas. Da mesma forma que a presença de grandes quantidades de óxido de ferro III $\left(\mathrm{Fe}_{2} \mathrm{O}_{3}\right)$ nas amostras de Tambaú, Porto Ferreira e Leme confere às mesmas coloração avermelhada. A perda ao fogo das amostras analisadas variou de 4,64\%, para a amostra de Leme, a $10,96 \%$, para a amostra de Ubarana. A perda ao fogo indica uma perda de massa em função do aumento da temperatura, e dá-se, principalmente pela umidade das massas, além da perda de hidroxilas dos hidróxidos, como $\mathrm{Al}(\mathrm{OH})_{3}$ e $\mathrm{Fe}(\mathrm{OH})_{3}$. Isso explica a maior perda ao fogo observada na amostra de Ubarana, assim como a menor perda ao fogo observada na amostra de Leme [21, 22]. Por apresentarem altos teores de óxidos alcalinos, as amostras podem ser chamadas de argilas fundentes que, normalmente são utilizadas como misturas para obtenção de argilas com propriedades físicas especiais [23].

A Tabela V apresenta os valores de retração linear, absorção de água e porosidade aparente dos corpos de prova queimados. Analisando-se a Tabela V, percebe-se que a amostra de Leme apresentou maior retração linear dentre todas as amostras analisadas, o que pode ser explicado pela alta quantidade de argila e silte em sua composição granulométrica $(86 \%)$ e pelo alto valor do limite de plasticidade $(25,9 \%)$.

Da mesma forma, a amostra de Porto Ferreira apresentou um alto valor de retração linear $(1,15 \%)$, mesmo tendo em sua composição granulométrica, baixo teor de argila e silte $(76 \%)$. Isso pode ser explicado pelo seu alto limite de plasticidade $(30,7 \%)$ e conseqüentemente pela grande quantidade de água necessária para sua conformação $(27,5 \%)$, já que o limite de plasticidade representa a quantidade mínima de água a ser adicionada a uma amostra 
Tabela IV - Composição química das amostras de solo.

[Table IV - Chemical composition of the soil samples.]

\begin{tabular}{cccccccccccc}
\hline Amostra & $\begin{array}{c}\mathrm{SiO}_{2} \\
(\%)\end{array}$ & $\begin{array}{c}\mathrm{TiO}_{2} \\
(\%)\end{array}$ & $\begin{array}{c}\mathrm{Al}_{2} \mathrm{O}_{3} \\
(\%)\end{array}$ & $\begin{array}{c}\mathrm{Fe}_{2} \mathrm{O}_{3} \\
(\%)\end{array}$ & $\begin{array}{c}\mathrm{MnO} \\
(\%)\end{array}$ & $\begin{array}{c}\mathrm{MgO} \\
(\%)\end{array}$ & $\begin{array}{c}\mathrm{CaO} \\
(\%)\end{array}$ & $\begin{array}{c}\mathrm{Na}_{2} \mathrm{O} \\
(\%)\end{array}$ & $\begin{array}{c}\mathrm{K}_{2} \mathrm{O} \\
(\%)\end{array}$ & $\begin{array}{c}\mathrm{P}_{2} \mathrm{O}_{5} \\
(\%)\end{array}$ & $\begin{array}{c}\text { Perda ao fogo* } \\
(\%)\end{array}$ \\
\hline $\begin{array}{c}\text { Tambaú } \\
\text { Porto }\end{array}$ & 66,77 & 0,904 & 15,64 & 6,32 & 0,057 & 1,36 & 0,32 & 0,12 & 2,40 & 0,119 & 6,04 \\
Ferreira & 59,50 & 0,875 & 17,38 & 7,43 & 0,074 & 2,94 & 0,58 & 1,23 & 3,86 & 0,183 & 5,42 \\
Ubarana & 60,32 & 1,350 & 21,10 & 3,85 & 0,034 & 0,28 & 0,12 & 0,13 & 1,65 & 0,120 & 10,96 \\
Leme & 68,18 & 0,614 & 14,42 & 4,88 & 0,088 & 1,81 & 0,32 & 0,31 & 4,20 & 0,110 & 4,64 \\
Itu & 65,18 & 1,282 & 16,84 & 6,81 & 0,066 & 0,44 & 0,23 & 0,07 & 0,94 & 0,088 & 7,68 \\
\hline
\end{tabular}

* Perda ao fogo realizada a temperatura de $1000^{\circ} \mathrm{C}$

Tabela V - Retração linear, absorção de água e porosidade aparente dos corpos de prova.

[Table V-Linear Shrinkage, water absorption and apparent porosity of the samples.]

\begin{tabular}{ccccccc}
\hline Local & $\begin{array}{c}\text { Retração } \\
\text { linear } \\
(\%)\end{array}$ & $\begin{array}{c}\text { Desvio } \\
\text { padrão }\end{array}$ & $\begin{array}{c}\text { Absorção } \\
\text { de água } \\
(\%)\end{array}$ & $\begin{array}{c}\text { Desvio } \\
\text { padrão }\end{array}$ & $\begin{array}{c}\text { Porosidade } \\
\text { aparente } \\
(\%)\end{array}$ & $\begin{array}{c}\text { Desvio } \\
\text { padrão }\end{array}$ \\
\hline Tambaú & 0,96 & 0,11 & 20,23 & 0,61 & 34,16 & 0,67 \\
Porto Ferreira & 1,15 & 0,10 & 24,18 & 0,36 & 37,59 & 0,31 \\
Ubarana & 0,76 & 0,08 & 16,34 & 0,14 & 29,16 & 0,20 \\
Leme & 1,46 & 0,16 & 18,73 & 0,26 & 31,75 & 0,34 \\
Itu & 0,83 & 0,09 & 16,55 & 0,25 & 29,64 & 0,45 \\
\hline
\end{tabular}

de solo para que o mesmo obtenha características moldáveis. Já a amostra de Ubarana apresentou o menor valor de retração linear dentre as amostras analisadas, já que, em sua composição granulométrica, verificou-se os menores teores de argila e silte $(72 \%)$, além do menor limite de plasticidade dentre todas as amostras estudadas (19,1\%), gerando assim a necessidade de baixa quantidade de água para sua conformação, o que resulta em um menor tempo de secagem, menor porosidade aparente, menor retração linear e, conseqüentemente, redução dos defeitos nos produtos finais, conforme ilustram as Figs. 6 e 7.

Os valores de absorção de água dos corpos de prova variaram entre $16,34 \%$ e $24,18 \%$, valores esses abaixo de $25 \%$, valor máximo de absorção de água para tijolos maciços e blocos de cerâmica vermelha. No entanto, considerando a produção de agregados para concreto, esses valores são considerados altos, já que a absorção de água da argila expandida (imersa em água por $24 \mathrm{~h}$ ) não ultrapassa o valor de $10 \%[4,24,25]$. Os corpos de prova de Ubarana e Itu foram os que apresentaram menores valores de absorção de água. Esse fato pode ser um indício de que a queima foi bem feita e que os corpos de prova tiveram uma boa densificação durante a queima, conseqüência dos valores de massa específica aparente dos corpos de prova, os maiores dentre os estudados $\left(1,785 \mathrm{~g} / \mathrm{cm}^{3}\right.$ e $1,791 \mathrm{~g} / \mathrm{cm}^{3}$, respectivamente). Além disso, os corpos de prova de Ubarana e Itu apresentaram as menores quantidades de material fundente $\left(\mathrm{Fe}_{2} \mathrm{O}_{3}+\mathrm{MgO}\right.$ $\left.+\mathrm{CaO}+\mathrm{Na}_{2} \mathrm{O}+\mathrm{K}_{2} \mathrm{O}\right)$ em suas composições $(6,03 \%$ e $8,49 \%$, respectivamente) e as menores quantidades de água para conformação (19,4\% e 18,2\%, respectivamente). Da mesma forma, os corpos de prova de Porto ferreira, por apresentarem a maior quantidade de material fundente em sua composição $(16,04 \%)$, uma das maiores quantidades de água para conformação $(27,5 \%)$ e a menor massa específica aparente dentre todas as amostras $\left(1,555 \mathrm{~g} / \mathrm{cm}^{3}\right)$, foram os que apresentaram a maior absorção de água dentre os corpos de prova estudados, $24,18 \%$, conforme ilustra a Fig. 8.

Já as amostras de Ubarana e Itu foram as que apresentaram os menores valores de porosidade aparente, $29,16 \%$ e $29,64 \%$, respectivamente, o que confirma o dado apresentado na Tabela V, mostrando que as duas amostras foram também

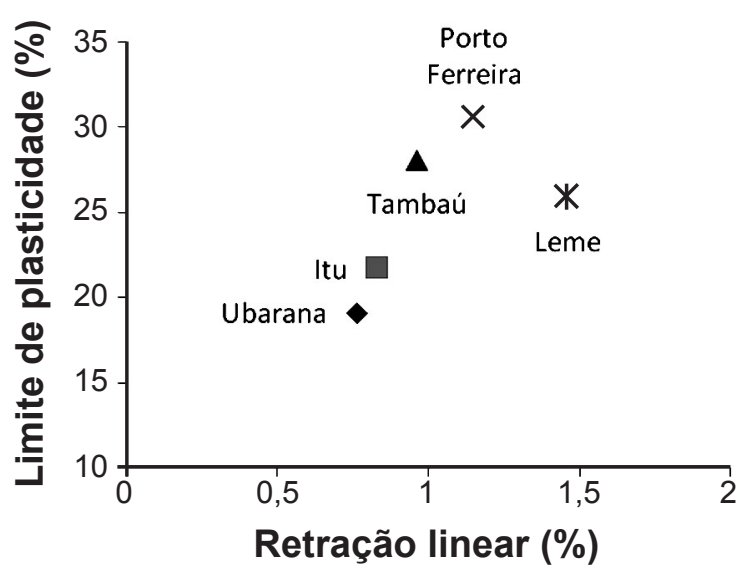

Figura 6: Retração linear das peças queimadas em função do limite de plasticidade das massas cerâmicas.

[Figure 6: Burned specimen's linear shrinkage due to ceramic material's plasticity limits.] 


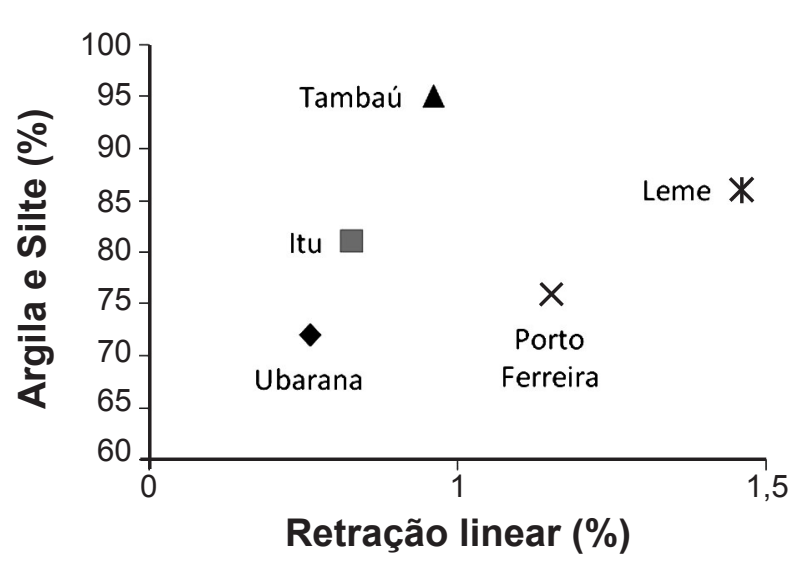

Figura 7: Retração linear das peças queimadas em função das quantidades de argila e silte das massas cerâmicas.

[Figure 7: Burned specimen's linear shrinkage due to the amounts of clay and silt of ceramic materials.]

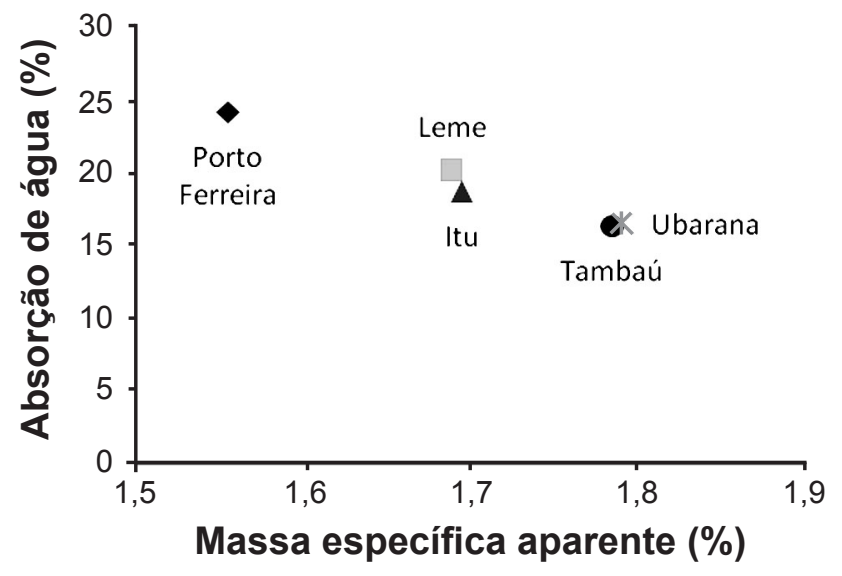

Figura 8: Massa específica aparente das peças queimadas em função de suas absorções de água.

[Figure 8: Burned specimen's specific mass due to their water absorption.]

Tabela VI - Valores de expansão por umidade, de massa específica aparente e de resistência à compressão dos corpos de prova queimados.

[Table VI - Values of moisture expansion, bulk density and compressive strength of the burned samples.]

\begin{tabular}{cccccccc}
\hline Local & $\begin{array}{c}\text { Temp. de } \\
\text { queima } \\
\left({ }^{\circ} \mathrm{C}\right)\end{array}$ & $\begin{array}{c}\text { Expansão } \\
\text { por umidade } \\
(\%)\end{array}$ & $\begin{array}{c}\text { Desvio } \\
\text { padrão }\end{array}$ & $\begin{array}{c}\text { Massa específica } \\
\text { aparente } \\
\left(\mathrm{g} / \mathrm{cm}^{3}\right)\end{array}$ & $\begin{array}{c}\text { Desvio } \\
\text { padrão }\end{array}$ & $\begin{array}{c}\text { Resistência à } \\
\text { compressão } \\
(\mathrm{MPa})\end{array}$ & $\begin{array}{c}\text { Desvio } \\
\text { padrão }\end{array}$ \\
\hline Tambaú & 900 & 0 & 0,10 & 1,689 & 0,022 & 43,5 & 10,9 \\
Porto Ferreira & 900 & 0,11 & 0,08 & 1,555 & 0,012 & 18,0 & 4,1 \\
Ubarana & 900 & 0 & 0,08 & 1,785 & 0,004 & 55,8 & 11,4 \\
Leme & 900 & 0 & 0,06 & 1,695 & 0,009 & 38,6 & 3,4 \\
Itu & 900 & $-0,86$ & 0,84 & 1,791 & 0,006 & 39,5 & 5,4 \\
\hline
\end{tabular}

as que apresentaram menores valores de absorção de água, $16,34 \%$ e $16,55 \%$, respectivamente. O mesmo ocorre com a amostra de Porto Ferreira, que por apresentar a maior quantidade de material fundente em sua composição dentre todas as amostras analisadas, alem da elevada quantidade de água para conformação, apresentou os maiores valores de absorção de água e de porosidade aparente dentre todas as amostra analisadas $(24,18 \%$ e $37,59 \%$, respectivamente).

Os dados de expansão por umidade, massa específica aparente e resistência à compressão dos corpos de prova são apresentados na Tabela VI. Todas as amostras, exceto a de Porto Ferreira e Itu, apresentaram expansão por umidade inferior a $0,06 \%$, valor máximo indicado para placas cerâmicas. A alta expansão por umidade apresentada pela amostra de Porto Ferreira $(0,11 \%)$ e o valor negativo da expansão por umidade apresentado pela amostra de Itu $(-0,86 \%)$ podem ser atribuídos ao elevado desvio padrão das medidas [26].

A massa específica aparente está diretamente ligada à porosidade aparente e absorção de água das peças, sendo que quanto menores esses valores, maiores os valores de massa específica aparente das peças queimadas, já que, quanto maior a densificação da matéria prima durante a queima, menos vazios existirão nas peças queimadas e maiores serão suas massas específicas. Dessa forma, observa-se que as amostras que apresentaram maiores valores de massas específicas aparentes foram as de Itu e Ubarana $\left(1,791 \mathrm{~g} / \mathrm{cm}^{3}\right.$ e $1,785 \mathrm{~g} / \mathrm{cm}^{3}$, respectivamente), que apresentaram também os menores valores de absorção de água (16,55\% e 16,34\%, respectivamente) e porosidade aparente $(29,64 \%$ e $29,16 \%$, respectivamente). Os corpos de prova de Porto Ferreira apresentaram o menor valor de massa específica aparente $(1,555 \mathrm{~g} / \mathrm{cm})$ e os maiores valores de absorção de água e porosidade aparente $(24,18 \%$ e $37,59 \%$, respectivamente), como ilustra a Fig. 9.

Para a produção de concretos, a massa específica dos agregados é de fundamental importância, já que influencia diretamente no valor da massa específica dos concretos. Os valores das massas específicas observadas para as peças de cerâmica vermelha encontram-se em um patamar intermediário, quando comparadas às massas específicas do basalto $\left(2,95 \mathrm{~g} / \mathrm{cm}^{3}\right)$ e da argila expandida (com dimensões de $15 \mathrm{a} 22 \mathrm{~mm})\left(0,7 \mathrm{~g} / \mathrm{cm}^{3}\right)$ [4]. Com relação à resistência à compressão, a amostra de Ubarana apresentou o maior valor (55,8 MPa) dentre as amostras estudadas, já que apresentou uma das maiores massas específicas, conferindo à mesma elevada densificação. Da mesma forma, por apresentar a menor massa específica, a amostra de Porto Ferreira 

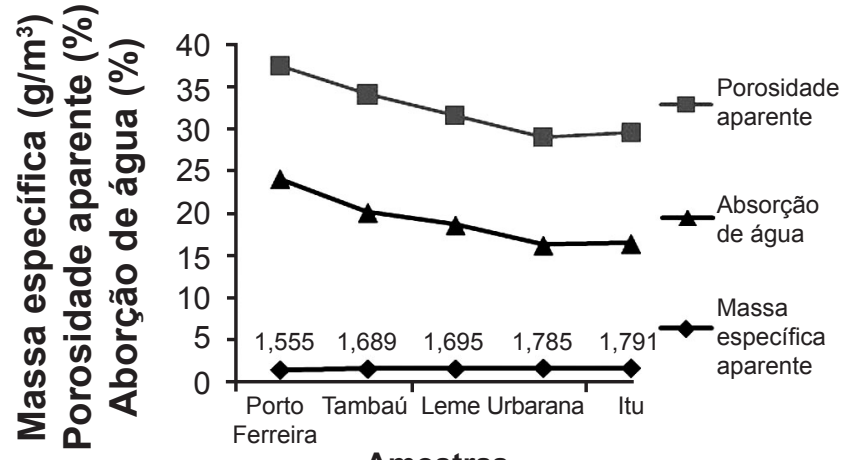

Amostras

Figura 9: Massa específica aparente, porosidade aparente e absorção de água dos corpos de prova queimados.

[Figure 9: Burned specimen's specific mass, apparent porosity and water absorption.]

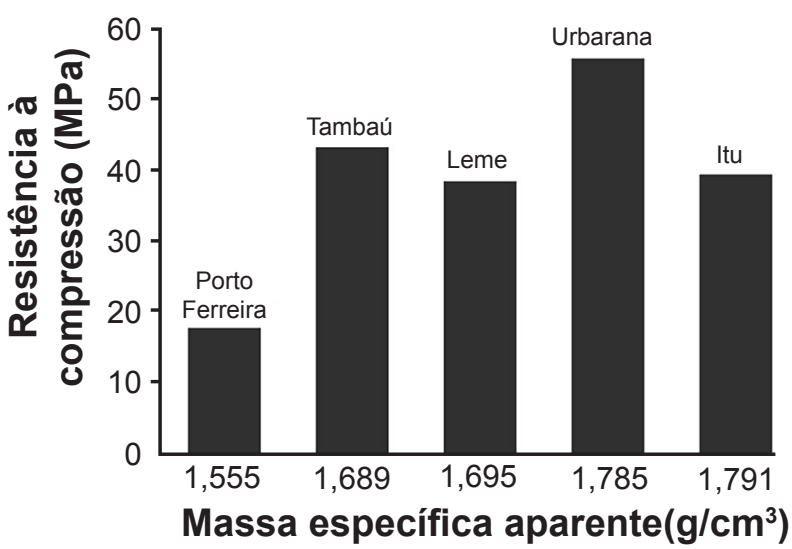

Figura 10: Resistência à compressão das peças queimadas em função de suas massas específicas aparentes.

[Figure 10: Burned specimen's compressive strength due to their specific mass.]

apresentou também a menor resistência a compressão dentre todas as amostras analisadas, conforme ilustra a Fig. 10. Os corpos de prova de Itu apresentaram resistência à compressão inferior aos corpos de prova de Ubarana e Tambaú, mesmo apresentando massa específica aparente superior às duas amostras. Esse comportamento pode ser explicado por defeitos nas peças queimadas, como trincas, ou pela necessidade de queima a temperaturas mais elevadas.

Ressalta-se aqui a grande variabilidade nos valores das propriedades dos corpos de prova das amostras analisadas. Esses resultados mostram-se importantes na escolha da massa cerâmica para a confecção dos agregados leves, já que quanto maior a massa específica dos agregados, maiores os valores de resistência à compressão e menores os valores de absorção de água e de porosidade aparente dos mesmos.

\section{CONCLUSÕES}

Há indicações de que a produção de agregados leves de argila calcinada para a utilização em concretos estruturais pode ser viável e que esses agregados apresentam características compatíveis com as determinadas para a utilização em concreto estrutural. As matérias primas coletadas são muito heterogêneas (por se tratarem de amostras de solo coletadas "in natura"). Todas as amostras apresentam altos teores de argila e silte em suas composições, o que confirma a alta plasticidade apresentada pelas mesmas (IP $>15 \%$ ). Os difratogramas de raios $\mathrm{X}$ indicam a presença de quartzo livre (um dos cristais formadores da fase vítrea) e de muscovita (cristal com características expansivas) em todas as amostras, porém, não foram encontradas a presença de montmorilonita em nenhuma das amostras. A composição química das amostras de solo indica a presença de altos teores de dióxido de silício $\left(\mathrm{SiO}_{2}\right)$ em todas as amostras. Além disso, a presença de $\mathrm{TiO}_{2}$ em quantidades superiores a $1 \%$ nas amostras de Itu e Ubarana, assim como a presença de grandes quantidades de óxido de ferro III $\left(\mathrm{Fe}_{2} \mathrm{O}_{3}\right)$ nas amostras de Tambaú, Porto Ferreira e Leme são os responsáveis pela coloração acinzentada e avermelhada dos corpos de prova produzidos com as matérias primas analisadas. Os valores de absorção de água dos corpos de prova queimados mantiveram-se abaixo do limite de absorção de água para tijolos maciços e blocos cerâmicos (25\%) e acima dos valores de absorção de água da argila expandida (10\%). A absorção de água, a porosidade aparente e a resistência à compressão estão inversamente relacionadas à massa específica e a densificação das peças, sendo que quanto maior a massa específica, maior a densificação das peças queimadas e menores os valores de absorção de água, de porosidade aparente e de resistência à compressão das mesmas.

\section{AGRADECIMENTOS}

À CAPES, ao CNPq e à FINEP pelo apoio financeiro, ao Laboratório de Mecânica dos Solos do Departamento de Geotecnia da EESC/USP, ao Laboratório de Construção Civil do IAU/USP, ao Instituto de Geociências da USP, ao laboratório de Construções Rurais e Ambiência da FZEA/ USP e às empresas Cerâmica Josemar Ltda., Morandin Produto Cerâmicos, Selecta blocos (Grupo Estrutural), Maristela Telhas Ltda. (Top Telha) e Cerâmica Vale do Mogi, por fornecerem matéria prima.

\section{REFERÊNCIAS}

[1] M. H. Zhang, O. E. Gjprv, ACI Mater. J. 88, 3 (1991) 240.

[2] T. A. Holm, T. W. Bremner, High strength lightweight aggregate concrete, in: S. P. Shah, S. H. Ahmad, Eds. "High performance concrete: properties and applications", McGraw-Hill, New York, EUA (1994) 341-374.

[3] J. A. Rossignolo, M. V. C. Agnesini, Concreto leve estrutural, In: G. C. Isaia, Ed., "Concreto: Ensino, Pesquisa e Realizações", 2 IBRACON, S. Paulo (2005) 1333-62.

[4] J. A. Rossignolo, Concreto leve estrutural: Produção, propriedades, microestrutura e aplicações, $1^{\text {a }}$ Ed., Ed. Pini, S. Paulo, SP (2009). 
[5] Y. Tezuka, Diss. Mestrado, Escola Politécnica da Universidade de S. Paulo, S. Paulo, SP (1973).

[6] H. S. Sobral, Concretos leves estruturais: Tipos e comportamento estrutural, Associação Brasileira de Cimento Portland - ABCP. S. Paulo, Publ. ET-86 (1996).

[7] A. C. J. Evangelista, L. C. D. Shehata, I. R. Almeida, Int. Cong. High-Performance Concrete, and Performance and Quality of Concrete Structures, Florianópolis, SC, Brasil (1996) 178-189.

[8] Serviço Brasileiro de Apoio às Micro e Pequenas Empresas - SEBRAE. Cerâmica vermelha para construção: telhas, tijolos e tubos, Estudos de Mercado SEBRAE/ESPM, S. Paulo, SP (2008) 40p.

[9] G. L. L. Cabral, Diss. Mestrado, Instituto Militar de Engenharia, Rio de Janeiro, RJ (2005) 358p.

[10] E. M. Cabral, R. J. Sá, R. K. Vieira, R. P. Vasconcelos, Cerâmica 54, 332 (2008) 404.

[11] A. L. C. P. Soares, F. G. S. Batista, G. L. L. Cabral, Projeto de fim de curso, Instituto Militar de Engenharia IME, Rio de Janeiro, RJ (1998).

[12] M. G. R. Santos, Diss. Mestrado, Universidade de Brasília - UnB, Brasília, DF (2007) 102p.

[13] R. R. Nascimento, Diss. Mestrado, Universidade Federal do Rio de Janeiro - UFRJ, Rio de Janeiro, RJ (2005) $171 \mathrm{p}$.

[14] ABNT Associação Brasileira de Normas Técnicas, NBR 6459: Solo - Determinação do Limite de Liquidez, Rio de Janeiro, RJ (1984).

[15] ABNT Associação Brasileira de Normas Técnicas, NBR 7180: Solo - Determinação do Limite de Plasticidade, Rio de Janeiro, RJ (1984).

[16] ABNT Associação Brasileira de Normas Técnicas,
NBR 7181: Solo - Análise Granulométrica, Rio de Janeiro, RJ (1984).

[17] ABNT Associação Brasileira de Normas Técnicas, NBR 6508: Grãos de Solos que Passam na Peneira de 4,8 mm - Determinação da Massa Especifica, Rio de Janeiro, RJ (1984).

[18] ABNT Associação Brasileira de Normas Técnicas, NBRNM 53: Agregado graúdo - Determinação de massa especifica, massa especifica aparente e absorção de água, Rio de Janeiro, RJ (2009).

[19] ABNT Associação Brasileira de Normas Técnicas, NBR 13818: Placas Cerâmicas Para Revestimento - Especificação e Método de Ensaio. Rio de Janeiro, RJ (1997).

[20] ABNT Associação Brasileira de Normas Técnicas, NBR 5739: Ensaio de compressão de corpos-de-prova cilíndricos de concreto, Rio de Janeiro, RJ (2007).

[19] C. A. S. Pérez, C. Paduani, J. D. Ardisson, D. Gobbi, A. Thomé, Cerâmica Industrial 15, 1 (2010) 38.

[20] S. Pracidelli, F. G. Melchiades, Ceram. Ind. 2, 1-2 (1997) 31.

[21] E. Grun, Diss. Mestrado, Universidade do Estado de Santa Catarina, Joinville, SC (2007) 60p.

[22] P. S. Santos, Ciência e Tecnologia das Argilas, $2^{\mathrm{a}}$ Ed., Edgard Blücher Ltda., S. Paulo, SP (1989) 496p.

[23] C. M. F. Vieira, H. F. Sales, S. N. Monteiro, Cerâmica 50, 315 (2004) 239.

[24] C. M. F. Vieira, J. N. F. Holanda, D. G. Pinatti, Cerâmica 46, 297 (2000) 14.

[25] C. M. F. Vieira, H. S. Feitosa, S. N. Monteiro, Ceram. Ind. 8, 2 (2003) 42.

[26] Centro Cerâmico do Brasil - CCB, disponível em http:// www.ccb.org.br, acesso em 29/09/2011.

(Rec. 22/03/2012, Rev. 14/05/2012, Ac. 16/07/2012) 